\title{
Gaussian Logarithms and Navigation
}

\section{Charles H. Cotter}

Gaussian logarithms are designed to facilitate finding the common logarithm of a sum or difference of two numbers whose common logarithms are known. The object of a table of Gaussian logarithms, sometimes known as Addition and Subtraction Logarithms, is to give $\log (a \pm b)$ by single entry when $\log a$ and $\log$ $b$ are known.

The usefulness of such a table appears first to have been described by $Z$. Leonelli in a book entitled Théorie des Logarithmes Additionnels et Déductif, published at Bordeaux in 1803 . Leonelli calculated a table but only a specimen of it was printed in the work cited. The first complete table of addition- and subtraction-logs, due to Karl Friederich Gauss (1777-1855), was published in I 8 I 2. Gauss' table gives values of $\log (I+x)$ and $\log \left(I+x^{-1}\right)$ tabulated respectively as $B$ and $C$ as correspondents to argument $\log x$ tabulated as $A .1$

Many formulae in spherical trigonometry which involve plus or minus signssuch as the spherical cosine formula for instance-are, as most navigators know, unsuitable for logarithmic computation. The use of Gaussian logarithms however overcomes this defect.

Let $x=(a+b)$ where $x, a, b$ are quantities containing trigonometrical functions of angles.

Let

$$
\log a-\log b=d=\log n
$$

Then

$$
n=a / b
$$

The formula for the addition- $\log (A)$ is :

$$
A=\log (n+1) / n
$$

and that for the subtraction- $\log (S)$ is:

$$
S=\log n /(n-1)
$$

Thus if $d=0.6$, which is the common $\log$ of 4 , then:

$$
A=\log (5 / 4)=0.097 \text { and } S=\log (4 / 3)=0.125
$$

In the table, therefore, we have:

$$
\begin{array}{ccc}
d & A & S \\
0.600 & 0.097 & 0.125
\end{array}
$$

Since

therefore

$$
A=\log (n+1) / n \text { and } n=a / b
$$

$$
\begin{aligned}
A & =\log (a / b+1) /(a / b) \\
& =\log (a+b) / a
\end{aligned}
$$


Thus:

$$
\begin{aligned}
\log a+A & =\log a+\log (a+b) / a \\
& =\log a(a+b) / a \\
& =\log (a+b)
\end{aligned}
$$

In other words if $A$, taken from a Gaussian log table using argument $d$, is added to $\log a$, the result is $\log (a+b)$. If $x=(a+b)$ then $x$ is the natural number corresponding to $\log (a+b)$.

Similarly since

therefore

$$
S=\log n /(n-1)
$$

Thus:

$$
S=\log a /(a-b)
$$

$$
\begin{aligned}
\log a-S & =\log a-\log a /(a-b) \\
& =\log (a-b)
\end{aligned}
$$

If, therefore, $S$ is subtracted from $\log a$ the result will be $\log (a-b)$, and if $x$ equals $(a-b)$ it is the natural number corresponding to $\log (a-b)$.

The above explanation of Gaussian logarithms is due to $H$. B. Goodwin2 whose interest in addition- and subtraction-logarithms appears to have been aroused through the publication of a small work ${ }^{3}$ in which the author, L. M. Berkeley, set out to demonstrate and to encourage navigators to use Gaussian logarithms for the purpose of facilitating the solution of great circle sailing problems.

Goodwin's contribution to the Nautical Magazine ${ }^{2}$ consisted of five parts, each part published separately. It appears that shortly after the first part was printed Goodwin discovered that Gaussian logarithms had, in fact, been introduced to nautical astronomers by a Yugoslav navigator named Ciro Carić some three years before Berkeley's book was published. Consequently in the second part of his contribution Goodwin described the work of Carić.

Captain Carić (1882-1962) was Professor of Mathematics and Navigation at the Naval Colleges of Dubrovnik and Kotor from 1913 to 1950. He was the author of a set of nautical tables ${ }^{4}$ which were published, first in Serbo-Croat and later in Italian, in which he introduced a novel method for solving the Marcq St. Hilaire problem using Gaussian logarithms. Before describing Carić's method, some remarks on Goodwin are relevant.

H. B. Goodwin, M.A., R.N. (1847-1927), for many years Naval Instructor at the Royal Naval College, Greenwich, was well known for his intense interest in nautical astronomy. Among numerous contributions in this field Goodwin's invention of the 'All-Haversine Formula' 5 concerns us here.

In the astronomical triangle $P Z X$, we have :

$$
\cos P=\frac{\cos Z X-\cos P Z \cos P X}{\sin P Z \sin P X}
$$

Employing the identities: 2 hav $\theta \equiv \mathbf{I}-\cos \theta$ and $2 \sin A \sin B \equiv \cos (A-B)$ $-\cos (A+B)$, it is easy to derive Goodwin's All-Haversine formula, viz :

$$
\text { hav } P=\frac{\text { hav } Z X-\text { hav }(P Z \sim P X)}{\text { hav }(P Z+P X)-\text { hav }(P Z \sim P X)}
$$


Goodwin re-arranged this formula to a form suitable for computing zenith distance as required in the Marcq St. Hilaire problem. This latter formula is :

$$
\text { hav } z=\text { hav }(p \sim c) \text { hav }\left(12^{\text {h }}-h\right)+\text { hav }(p+c) \text { hav } h
$$

where $z$ is zenith distance, $P$ is polar distance, $c$ is co-latitude, and $h$ is hour angle. It was first announced in print in $192 \mathrm{I}$. In that year Goodwin mentioned it to his friend Captain Alberto Alessio of the Royal Italian Navy. Alessio was impressed with its symmetry and made the formula the subject of a communication to the Italian Journal Rivista Marittima, in which journal the formula appeared in November 1921 . In his communication Alessio quoted Goodwin's suggestion of arranging the haversine table to give natural- and logarithmichaversines of $\theta$ on left-hand pages, and natural- and logarithmic-haversines of $\left(12^{h}-\theta\right)$ on right-hand pages. With this arrangement the proposed formula for computing zenith distance would provide a ready solution.

It is interesting to reflect that Alessio's remarks printed in an Italian journal at the time would most certainly have been noticed by Captain Carić, and it seems not improbable that Carić's idea for his Tavole Nautiche might well have been sparked off after reading Alessio's letter in Rivista Marittima. Captain Carić however used a notation different from that of Goodwin. Carić's formula is :

$$
\sin ^{2} z / 2=\sin ^{2} P / 2 \cos ^{2}(\phi+\delta) / 2+\cos ^{2} P / 2 \sin ^{2}(\phi-\delta) / 2
$$

where $z$ is zenith distance, $P$ is hour angle, and $\phi$ and $\delta$ are latitude and declination respectively.

Goodwin's suggestion for a re-arranged haversine table was improved considerably by Caric through the latter's use of Gaussian logarithms.

The very compact haversine table in Tavole Nautiche occupies only twelve pages. The upper half of each page gives log haversines of angles at minute-of-arc intervals, and the lower half gives log haversines of corresponding supplementary angles. In addition to the log haversine table Carić includes a Gaussian log table occupying two facing pages, and this table obviates the need for a table of natural haversines. These features result in a reduction, when using Carić's method, in the number of page-openings required in sight reduction as compared with those required in the haversine methods normally used.

The following problem and solution, taken from Tavole Nautiche, illustrates Carić's method. Example: Given hour angle $(P)=4^{\mathrm{h}} 15^{\mathrm{m}} 46^{\mathrm{s}}$; latitude $(\phi)=$ $13^{\circ} 30^{\prime}$ S. ; declination $(\delta)=7^{\circ} 23^{\prime}$ N., find zenith distance $(z)$.

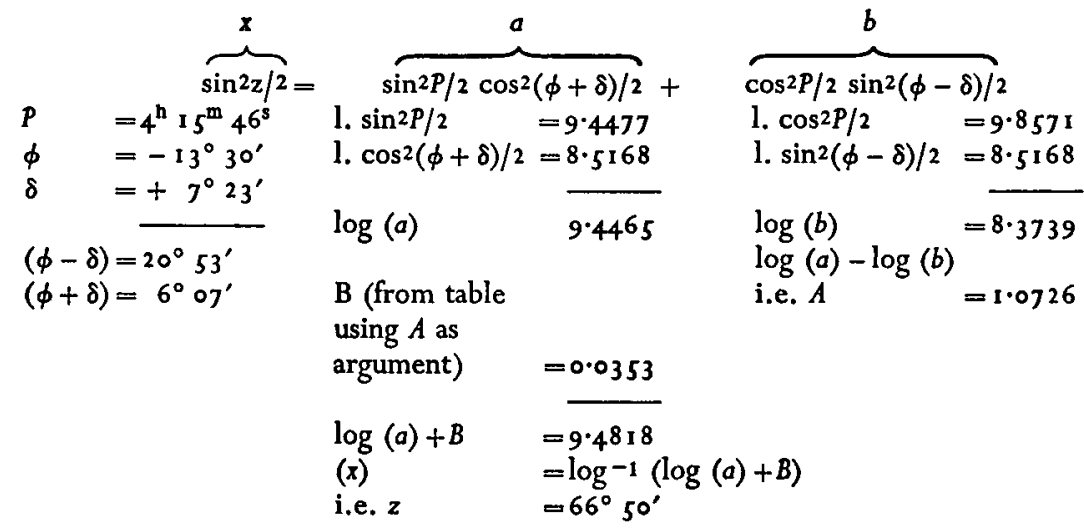


The first four logarithms required in the above solution are obtained from three page-openings of Carić's twelve-page table. By subtracting $\log (b)$ from $\log (a)$ quantity $A$ is obtained. The Gaussian $\log$ table is entered with $A$ and $B$ is extracted. $B$ is added to $\log (a)$ and the sum gives the log haversine of the required zenith distance $(z)$.

In a letter ${ }^{6}$ dated 1951 , the Rev. Keir Moillet wrote with enthusiasm about the Yugoslav Professor's method, and expressed surprise that no English language edition of Tavole Nautiche had been published. In the light of Keir Moillet's letter it is interesting to consider Goodwin's comments made in relation to the prospects of Gaussian logarithms for navigational and nautical astronomical purposes:

'The period of incubation', wrote Goodwin, 'for a new nautical method is generally a lengthy one ... perhaps 20 or 30 years or so, but if, as is claimed for the Gaussian logarithms, a novelty is of real merit, it is pretty sure to win through in the end.'

Keir Moillet's letter, which in a sense seemed like a plea that Carić's method should be widely known, was written between 20 and 30 years after Goodwin made his prophecy. Sad as it may seem, the interesting aid to computation named after one of the most eminent mathematicians of the nineteenth century, has failed utterly to win the approval of navigators generally.

ACXNOWLEDGMENTS. The inspiration to study the work of Ciro Caric stemmed from my introduction to Miss Tonka Carić, one-time student at the University of Wales Institute of Science and Technology at Cardiff. Miss Carić is a niece of the late Ciro Carić and is at present a lecturer in English at Viša Pomorska, Škola, Kotor, the same nautical college at which Captain Carić occupied the Chair in Mathematics and Navigation.

It is my pleasure to record my gratitude to Miss Carić and also to her colleague Captain Jovo Tauzovic who went to a great deal of trouble to procure for me a copy of the long out-of-print Tavole Nautiche.

\section{REFEREN CES}

1 Glaisher, J. W. L. Mathematical Tables, Encyclopaedia Britannica 11 th Edition 1911.

2 Goodwin, H. N. (1926). The Gaussian Logarithms-Their Nature, Theory and Use. Nautical Magazine, Vol. 116.

3 Berkeley, L. M. (1926). Great Circle Sailing. New York.

4 Carić, Ciro. (1923).Tavole Nautiche. Cattaro (Kotor).

5 Goodwin, H. B. (1910). The Haversine in Nautical Astronomy, U.S. Naval Institute Proceedings. Vol. 36. (also Nautical Magazine, Vol, 100).

6 Keir Moillet, B. R. (195I). This Journal, 4, 105. 